\title{
On Looking Inward and Being Scientific: A Tribute to G.L. Engel, MD
}

\author{
Giovanni A. Fava \\ Department of Psychiatry, State University of New York at Buffalo, N.Y., USA, and Department of Psychology, \\ University of Bologna, Italy
}

George Engel, the father of modern psychosomatic medicine, died just before the turn of the century. We are now in the position of stating that he has been one of the century's most influential physicians at the interface between medical and behavioral sciences. He was universally known for the biopsychosocial model [1]. However, the beginning of a paper that he wrote for our journal as a tribute to his long-standing colleague and friend, Arthur Schmale [2], could also disclose that his '... greatest contribution remains hardly known even to his admirers. That has been his challenge to the tradition disallowing introspection and dialogue as scientific instrumentalities'. This issue of the journal is a tribute to his timeless legacy.

The first special article, 'Psychosomatic medicine: emerging trends and perspectives', attempts to carry his message through the new century. To discuss, support and comment on psychosomatic medicine (as is presented by the three accompanying editorials) is the first and most immediate way of remembering Engel's work. A comprehensive discussion of psychosomatic medicine was probably long overdue. We welcome and challenge comments, particularly of those who would like to relinquish the term psychosomatic medicine. The second special article, on psychosomatic assessment of functional gastrointestinal disorders, offers a clinical translation of Engel's clinical observations concerned with the giving-up reaction and the process of somatization [2,3]. The review by Kroenke and Swindle further elaborates the issue of somatization by reviewing the controlled clinical trials concerned with cognitive behavioral therapy.

Engel has emphasized the role of clinical observation, the neglected basic method of medicine [4]. He wrote 'We must put an end to the arrogant attitude that depreciates the contributions which can be made by the sensitive clinical observer, that pronounces only a long immersion in the chemistry laboratory as the proper preparation for a scientific career' [4, p. 852] at a time (1965) when such an attitude was only emerging. The fourth special article deals with clinimetrics, the science of clinical measurements. It reports on the development of a clinical index for improving the reliability of clinical judgement in Cushing's syndrome. One of Engel's earliest papers had to do with clinical observation in Addison's disease [5].

The last special article is concerned with teaching, an issue that was of primary concern to George Engel [6]. We realize that this is only a partial tribute to his work and to the challenge entailed by his thinking [7]. 'Thank you for your insight and wisdom and all you have taught me' [2, p. 68] is what physicians have to say to him.

\section{References}

1 Engel GL: The need for a new medical model: A challenge for biomedicine. Science 1977;196:129-136.

2 Engel GL: On looking inward and being scientific. A tribute to Arthur $\mathrm{H}$. Schmale, MD. Psychother Psychosom 1990;54:63-69.

3 Engel GL: From biomedical to biopsychosocial. Psychother Psychosom 1997;66:57-62.

4 Engel GL: Clinical observation. The neglected basic method of medicine. JAMA 1965;192:849-852.

5 Engel GL, Margolin SG: Neuropsychiatric disturbances in internal disease. Arch Intern Med 1942;70:236-259.

6 Engel GL: Enduring attributes of medicine relevant to the education of the physician. Ann Intern Med 1973;78:587-593.

7 Engel GL: How much longer must medicine's science be bound by a seventeenth century world view? Psychother Psychosom 1992;57:3-16.

\section{KARGER \\ Fax +4161306 1234 \\ E-Mail karger@karger.ch} www. karger.com (c) 2000 S. Karger AG, Basel

0033-3190/00/0694-0169\$17.50/0

Accessible online at:

www. karger.com/journals/pps

\section{G.A. Fava, MD}

Dipartimento di Psicologia, Università degli Studi di Bologn

Viale Berti Pichat 5

I-40127 Bologna (Italy)

Fax +39051243086 